Recibido: 01/04/2021 --- Aceptado: 02/08/2021 --- Publicado: 16/09/2021

\title{
POPULISMO POLÍTICO EN TIEMPOS DE COVID. ANÁLISIS DE LA ESTRATEGIA DE COMUNICACIÓN DE DONALD TRUMP Y BORIS JOHNSON EN TWITTER
}

\section{POLITICAL POPULISM IN COVID'S TIME. ANALYSIS OF DONALD TRUMP AND BORIS JOHNSON COMUNICATION STRATEGY ON TWITTER}

Sergio Toro González: Universidad de Sevilla. España. stg1985@hotmail.com

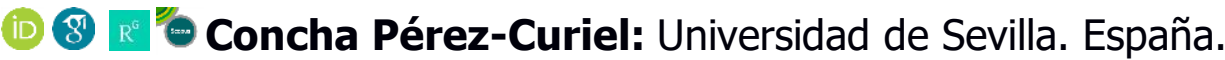
cperez1@us.es

Cómo citar el artículo:

Toro González, S. y Pérez-Curiel, C. (2021). Populismo político en tiempos de COVID. Análisis de la estrategia de comunicación de Donald Trump y Boris Johnson en Twitter. Revista de Comunicación de la SEECI, 54, 1-24. http://doi.org/10.15198/seeci.2021.54.e700

\section{RESUMEN}

Introducción: La sobreactivación informativa que la pandemia ha provocado en las Redes Sociales de la gobernanza internacional describe un escenario marcado por la polarización y el populismo político. Twitter se convierte en una plataforma de referencia para la comunicación no mediada. El uso de esta herramienta como parte de la estrategia de los líderes políticos reactiva la alarma de las organizaciones mundiales ante el incremento de la desinformación. Metodología: con el objetivo de conocer qué marcas identifican el discurso populista y qué efectos producen en la esfera pública, se aplica una metodología de triple enfoque (cuantitativo-cualitativodiscursivo) sobre los tuits publicados durante el primer periodo de alarma de la COVID19 por Donald Trump (@realDonaldTrump), presidente de Estados Unidos y Boris Johnson (@BorisJohnson), primer ministro del Reino Unido. Discusión y Conclusiones: Los resultados revelan la presencia de la falacia como marca del discurso populista, la proyección de los mensajes de Twitter en los medios de comunicación y una influencia en la audiencia social, causa probable de la desafección ciudadana ante la política.

PALABRAS CLAVE: Desinformación -Twitter - COVID-19 - Populismo - Líder Influencia - Audiencia Social 


\section{ABSTRACT}

Introduction: the information overactivation that the pandemic has caused in the social networks of International Governance describes a scenario marked by polarization and political populism. Twitter becomes a reference platform for unmediated communication. The use of this tool as part of the strategy of political leaders reactivates the alarm of global organizations in the face of increased disinformation. Methodology: in order to know which brands identify populist discourse and what effects they produce in the public sphere, a triple approach methodology (quantitative-qualitative-discursive) is applied on tuits published during the first COVID-19 alarm period by Donald Trump (@realDonaldTrump), United States president and Boris Johnson (@BorisJohnson), United Kingdom president. Discussion and conclusions: the results reveal the presence of fallacy as a hallmark of populist discourse, the projection of Twitter messages in the media and an influence on the social audience that could be the cause of citizen disaffection with politics.

KEY WORDS: Twitter - COVID-19 - Political - Populism - Leader - Influence - Social Networks - Speech

\section{POPULISMO POLÍTICO EM TEMPOS DE COVID. ANÁLISE DA ESTRATÉGIA DE COMUNICAÇÃO DE DONALD TRUMP E BORIS JOHNSON NO TWITTER}

\section{RESUMO}

Introdução: A super ativação de informações que a pandemia causou nas Redes Sociais de políticos a nivel internacional descreve um cenário marcado pela polarização e pelo populismo político. O Twitter passa a ser uma plataforma de referência para comunicação não mediada. O uso dessa ferramenta como parte da estratégia dos dirigentes políticos reativa o alarme das organizações mundiais diante do aumento da desinformação. Metodologia: com o objetivo de saber quais marcas identificam o discurso populista e quais os efeitos que produzem na esfera pública, uma metodologia de tripla abordagem (quantitativo-qualitativa-discursiva) é aplicada aos tweets publicados durante o primeiro período de alarme do COVID-19 por Donald Trump (@realDonaldTrump), presidente dos Estados Unidos e Boris Johnson (@BorisJohnson), primeiro-ministro do Reino Unido. Discussão e Conclusões: Os resultados revelam a presença da falácia como marca do discurso populista, a projeção de mensagens do Twitter na mídia e influência no público social, provável causa do descontentamento do cidadão com a política.

PALAVRAS CHAVE: Desinformação -Twitter - COVID-19 - Populismo - Líder Influência - Público Social. 


\section{INTRODUCCIÓN}

La Organización Mundial de la Salud (OMS), el 13 de febrero de 2020, a través de su director general D. Tedros Adhanom Ghebreyesus, solicita a los gigantes tecnológicos que tomen medidas sistemáticas inmediatas para detener el flujo de información errónea sobre la salud y la crisis de salud pública. Se trata de un fenómeno definido como infodemia ${ }^{1}$ que alerta sobre la desinformación y el aumento de fake news relacionadas con la COVID-19 y los efectos que produce sobre la ciudadanía (Fernández-Torres et al., 2021).

Al centrar la investigación sobre esta temática, seleccionamos a grandes líderes mundiales que fueran referente y que su grado de influencia fuese notorio, concretando la ideología de derecha, ya que las fake news adquieren una connotación derechista desde que el gobierno del Partido Nacionalsocialista Obrero Alemán (NSDAP), a partir de los años 20, destinara ingente cantidad de recursos a difundir información falsa, bulos, manipulaciones o difamaciones. Estas noticias falsas se vinculan a la Propaganda Nazi, dirigida por Joseph Goebbels. Un discurso que además de reconocer las bondades del nazismo, ataca a sus rivales políticos y esconde las miserias del régimen (Cuervo, 2015). Este fenómeno se proyecta hoy en un contexto de posverdad que afecta a la política y a sus gobernantes, especialmente en el ámbito de las redes sociales.

Los líderes escogidos tienen gran vinculación en su formato propagandísticos y en el populismo de extrema derecha que utilizan (Pérez-Curiel et al., 2021) con precedentes en las redes sociales que justifican la elección. En concreto, Twitter decide eliminar la cuenta de Donald Trump (@realDonaldTrump), entre otras razones, por ser el autor de las teorías conspirativa que acusan a China del mal endémico, por el anuncio de medicamentos sin respaldo científico (Chadwick; Cereceda, 2020), por la denuncia sobre la eficacia de las vacunas de otros países o por su actitud de politizar y restar importancia al virus, señas de identidad del discurso populista.

Por su parte, Boris Johnson defiende la teoría denominada 'Inmunidad del rebaño' que justifica la máxima propagación del virus, llegando a tanta gente que el virus no encuentre a más personas a las que infectar. Una estrategia propia del populismo que lo presenta como mesías y salvador de la comunidad (Hawkins, 2016).

\subsection{Crisis sanitaria mundial}

"Hemos llegado a la conclusión de que la COVID-19 puede considerarse una pandemia" (OMS, 2020). Con esta afirmación anunciaba la Organización Mundial de la Salud, el pasado 11 de marzo de 2020, que el virus COVID-19 era declarado como pandemia, tras detectar más de 118.000 casos en 114 países, y 4.291 personas fallecidas a causa de esta enfermedad.

\footnotetext{
${ }^{1}$ Infodemia: es una sobreabundancia de información, en línea o en otros formatos, e incluye los intentos deliberados por difundir información errónea para socavar la respuesta de salud pública y promover otros intereses de determinados grupos o personas.
} 
La expansión vírica ha llegado a todos los rincones del mundo, con gran afección en Europa y América. La trascendencia y los efectos de la COVID-19 serán difíciles de cuantificar incluso en el marco de una sociedad avanzada, dominada por los algoritmos y la inteligencia artificial (Xifra, 2020; Hansen et al., 2017; Powers y Kounalakis 2017), ya que la situación de crisis social, sanitaria, política y económica ha puesto a prueba los sistemas de producción científica (Kupferschmidt, 2020).

El contexto político, de los presidentes seleccionados para el estudio, describe diferentes actuaciones contra la pandemia. El inicio del tratamiento de la enfermedad en Reino Unido y las medidas tomadas por Boris Johnson, para reducir la mortalidad y el alcance de la COVID-19, fueron cuestionadas por la comunidad científica, en el informe 'Report: Impact of non-pharmaceutical interventions (NPIs) ${ }^{\prime 2}$. El primer ministro sostiene, al inicio de la pandemia, que, en ausencia de vacuna, se deben evaluar medidas de salud pública, conocidas como intervenciones no farmacéuticas (ISFL) que combinan el aislamiento domiciliario, la cuarentena y el distanciamiento social principalmente de los ancianos y personas de riesgo, complementándose en su caso con el cierre de escuelas y universidades.

En Estados Unidos, el 13 de marzo, dos días después de que la OMS calificara de pandemia el brote de la COVID-19, el presidente Donald Trump proclama la emergencia nacional en todo el país, aunque apuesta por el mantenimiento de la economía ante la propagación de la enfermedad.

\subsection{Comunicación en periodo de alarma de la COVID-19}

Durante la propagación de la pandemia de la COVID-19, asistimos a una sobreexposición de información política (Castillo-Esparcia et al., 2020) derivada de las múltiples comparecencias públicas de los líderes, dada la necesidad de explicar a la ciudadanía lo que está sucediendo. Esta autopublicidad implica unos riesgos para la imagen de los principales representantes, provocados por el desconocimiento de esta situación y las consecuencias de la estrategia implantada. En este sentido, la comunicación se convierte en una importante aliada de la gestión política, social, institucional y sanitaria (Costa-Sánchez y López-García, 2020).

En un momento en el que los organismos gubernamentales centran sus esfuerzos en luchar contra la enfermedad, los profesionales de la información deben jugar un papel relevante para detener la propagación de la información errónea relacionada con la pandemia (Tandoc, 2020), produciendo, según los expertos, un crecimiento masivo de fact-checks ${ }^{3}$ con motivo de la COVID-19 (Brennen, 2020), utilizando estos canales de comunicación como fuentes informativas sobre la pandemia (Gil-Ramírez et al., 2020). La implosión de una situación crítica y de riesgo para la población mundial,

\footnotetext{
${ }^{2}$ https://spiral.imperial.ac.uk/bitstream/10044/1/77482/15/2020-03-16-COVID19-Report-9Spanish.pdf

${ }^{3}$ fact-checks: definición utilizada para comprobar que todos los datos de un escrito, una noticia, un discurso, etc. son correctos
} 
como la provocada por la COVID-19, ligada a niveles de máxima inseguridad e incertidumbre, dispara los índices de fake news y de bulos en las redes (Pérez-Dasilva et al., 2020). Incluso, deriva en una activación de mensajes institucionales sobre el coronavirus, a menudo no comprobados, que se convierten en caldo de cultivo para los usuarios anonimizados de la red (Pérez-Curiel y Velasco-Molpeceres, 2020).

\subsection{Populismo y contexto político}

El denominado Populismo 2.0 (Gerbaudo 2014) se instala como estrategia comunicativa de algunos líderes para difundir y viralizar el mensaje, salvando la dificultad de acceso que encuentran en los medios convencionales (Shoemaker, Vos, 2009; Groshek, Engelbert, 2013) controlados por las élites (Van-Kessel; Castelein, 2016).

Un informe publicado por The Guardian (2019), sobre una muestra de 40 países, constata que el número de líderes populistas se ha duplicado en el siglo XXI. Concretamente, en Europa la polarización social y la crisis de los refugiados ha sido un catalizador para los populistas de derechas y para la transformación de partidos no populistas en partidos populistas (Mudde, 2016). El discurso populista de ultraderecha se instala en medios y redes y consigue resultados electorales sin precedentes (AlonsoMuñoz y Casero-Ripollés, 2019) (Bosch; Brunet; Rosiñol, 2017). El análisis de The Guardian muestra cómo los populistas triplican su número entre 1998 y 2018, obteniendo suficientes votos para colocar a sus líderes en posiciones gubernamentales en 11 países.

El partido republicano, con Trump a la cabeza, ganó las elecciones de 2016, alcanzando el $47.3 \%$ de los votos que suponía 60.541 .308 votantes y 306 escaños, superando los 232 conseguidos Hillary Clinton. Durante esta campaña, un estudio de la Universidad del Sur de California (Bessi y Ferrara, 2016), analiza 20 millones de tuits generados entre el 16 de septiembre y el 21 de octubre y escritos por unos 2.8 millones de usuarios. Se comprueba que aproximadamente 400.000 publicaciones eran bots (19\%) distorsionando el debate en Twitter, en su gran mayoría a favor de Trump.

Esta última teoría, de la situación que propició el triunfo de Trump en 2016, queda refrendada por diferentes estudios, como los obtenidos por investigadores de la Universidad de Oxford, dirigidos por Philip Howard, que hicieron seguimiento a más de 19 millones de tuits entre el 1 y el 9 de noviembre, al igual que por el Centro de Estudios para Periodistas, que llegó a contabilizar que el $80 \%$ de la actividad en Twitter, a favor de Trump, fue generada por estos bots (Hermida 2016).

Johnson, por la parte europea, se sirvió del uso de bots, utilizados como estrategia de influencia sobre la ciudadanía inglesa. La vinculación con la empresa de análisis 'Cambridge Analytica'4, empresa acusada de adueñarse de datos de usuarios de

\footnotetext{
${ }^{4}$ Cambridge Analytica: es una consultoría analítica que habría empleado su plataforma para obtener de forma irregular los datos de 87 millones de usuarios que utilizaban Facebook. Siendo utilizados en las elecciones presidenciales de Estados Unidos para que Donald Trump llegara a ser presidente.
} 
Facebook sin sus consentimientos ni conocimientos del uso; o los indicios de relaciones con Rusia y su intromisión en la estrategia viral del Brexit, son elementos por estudiar y determinar, según las declaraciones de Brittany Kaiser en el documental 'El Gran Hackeo ${ }^{\prime 5}$ y en la comisión de seguimiento que se realizó en el parlamento inglés.

Los partidos de derecha o conservadores, a nivel mundial se enfrentan a cambios ideológicos hacia "la derecha de sus derechas". En los últimos años, han aparecido nuevos partidos de ideología extrema (Acha, 2017) para ocupar ese espacio en función de factores socioeconómicos, psicológicos, políticos o internacionales (Ebata 1997) que ya no representan los partidos asentados. Definen a un líder carismático, con un lenguaje sencillo, propio de la gente común, que traslada un mensaje con fuerte carga ideológica y emocional (Taggart, 2020). Los líderes, establecen una demagogia demostrada, que evoluciona en oclocracia ${ }^{6}$, entendiéndose el concepto como la consecuencia de una acción demagógica, que se presenta en el peor de los sistemas políticos y el último ápice de degeneración de poder. Demagogia y populismo de la muchedumbre representada en una figura política, frente al pueblo como poder de gobernabilidad. Líderes que se encargan de erigirse en representantes de un todo, cuando apenas lo hacen de las minorías, sin ser nunca, en realidad, el gobierno de un pueblo (Mackintosh, 1791)

Además de las acciones que acometen en su gobernabilidad, los líderes de los partidos de ultraderecha, focalizan su atención en la campaña electoral y en las redes sociales como motor de influencia (Orozco, 2021) y de viralización (López- García, 2016; Dader \& Campos-Domínguez, 2017), usando políticas de deslegitimación de proceso electorales y mensajes populistas (Pérez-Curiel et al., 2021).

\subsection{Influencers de la política. Factor causal de la desinformación}

La revolución digital en el siglo XXI ha multiplicado, en redes, el grado de influencia de los políticos, así como su capacidad consciente para producir desinformación, basados en un uso profesional de la falacia y la propaganda. Se instala la política de la posverdad en la que valen más la manipulación de la ignorancia, y los sentimientos o emociones de la ciudadanía, que la argumentación racional (Boczkowski, 2016; Urmeneta, 2017). En el contexto digital se posiciona al ciudadano en el papel de receptor que ofrece feedback inmediato, con los riesgos que supone esta distorsión para la intención del discurso. Por el contrario, esta digitalización sí favorece a la gestión de la transparencia, imprescindible para la nueva información dirigida a la ciudadanía, a través de plataformas ciudadanas (Alonso-Muñoz y Casero-Ripollés, 2017).

La tendencia hacia la desinformación crece como un virus (Pérez- Curiel y VelascoMolpeceres, 2020; Román-San Miguel, Sánchez-Gey \& Elías, 2020; Elías, 2018), con un poder peligroso para la democracia (Coughlan; Valadier, 2017). La influencia del

\footnotetext{
${ }^{5}$ https://www.documaniatv.com/ciencia-y-tecnologia/el-gran-hackeo-video a56bd7bdd.html

${ }^{6}$ Oclocracia: proviene del griego y está formada por la raíz chlo, que quiere decir multitud, y por cratos, que se traduce como gobierno. Así, en su sentido literal la oclocracia es el gobierno de la multitud.
} 
populismo (Pérez-Curiel, 2020) se une a la desconfianza o la apatía de la ciudadanía hacia los partidos o los representantes políticos o, incluso, hacia otras lacras como la corrupción (Hernández-Santaolalla y Sola-Morales, 2019). En paralelo, la revolución digital multiplica en redes, especialmente en Twitter, el grado de impacto de los políticos sobre los usuarios, y sobre la configuración de la agenda mediática (Montoya \& Vandehey, 2009; Pérez-Ortega, 2014; Rampersad, 2009). En esta línea, Krane (2010) publica un trabajo centrado en el análisis de los contenidos difundidos en Twitter por tres medios, The New York Times, CNN y NPR que refuerza la teoría de que existe una relación directa entre los contenidos divulgados por los medios y los temas que con mayor frecuencia son abordados por los usuarios en la red.

Tras este análisis, el papel de Donald Trump, como político influencer en las redes, cobra fuerza. El líder demuestra capacidad para movilizar las opiniones, generar reacciones sobre diferentes elementos concretos, incrementar la audiencia y los niveles de participación, mediante la dinamización de un lenguaje simple, breve, rítmico y casi silábico, aspectos que disfrazan un discurso de dominación, empoderamiento y liderazgo (Pérez-Curiel y Limón-Naharro, 2019). Así mismo, el avance del populismo en Europa, posiciona los líderes como nuevos influencers digitales. Nos centramos en Boris Johnson que a través de Twitter encuentra un escenario para la difusión, interacción, movilización y personalización del candidato como estratega, en la selección de temas y en el uso de la propaganda y la falacia (Bravo, 2020).

En el sentido señalado, los acontecimientos publicados pasan a un segundo plano y el político se posiciona como destacado, además de convertir la publicación en noticia, posicionarla en la red e impulsar la viralización, utilizando los recursos de la propaganda en el discurso (Nocetti, 1990; Van Dijck, 2015). En la actualidad se cuestiona su actividad en las redes más que, su programa electoral, su imagen como líder, la ideología que representan o el partido que regentan, debido a la polarización que confronta a la izquierda y la derecha en el ámbito internacional.

El discurso populista de los líderes en Twitter sobre la COVID-19 genera un índice relevante de desinformación que afecta a la agenda mediática y a la percepción ciudadana sobre la pandemia.

\section{METODOLOGÍA}

En el contexto de la COVID-19, el discurso institucional de los gobernantes en Twitter favorece la falacia y el bulo, por ende, puede incrementar la confusión y la desconfianza ciudadana. En determinados perfiles de políticos, como los de Donald Trump y Boris Johnson abundan características del populismo de extrema derecha que definen estrategias de comunicación para la construcción del mensaje en Twitter. Se trata además de líderes que coinciden en un discurso basado en la conspiración y el negativismo ante los efectos de la COVID-19. La influencia posterior de este discurso en los medios es otro factor que incrementa los efectos sobre la ciudadanía.

En esta línea se establecen una serie de preguntas de investigación: 
PI. 1. ¿Se consideran las falacias, las fake news y la desinformación marcas del discurso de los líderes populistas en Twitter?

PI. 2. ¿Los posts publicados por los líderes en las redes afectan a la programación de la agenda habitual de los medios tradicionales?

PI. 3. ¿Qué indicadores del populismo extremo se localizan en los mensajes publicados en Twitter y los medios?

La aplicación de una metodología cuantitativa, cualitativa y discursiva en las cuentas de Twitter de los candidatos seleccionados, junto con las consideraciones teóricas expuestas, generan el planteamiento de los siguientes objetivos:

1. Conocer la actividad de los líderes políticos en las redes sociales, su influencia en los usuarios y la veracidad de sus publicaciones.

2. Analizar la presencia de las marcas del discurso populista en los mensajes publicados por Donald Trump y Boris Johnson en Twitter.

3. Comprobar qué proyección ha alcanzado la estrategia discursiva de los líderes en la agenda setting de los medios.

Para la realización del análisis de contenido intervienen diferentes agentes. Se ha realizado un estudio en profundidad mediante revisión bibliográfica. A ello se suma, una metodología de análisis de contenido comparado de triple enfoque: cuantitativo, cualitativo y discursivo (Lopéz-Noguero, 2002; Krippendorff, 2012; Silverman, 2016; Van-Dijk, 2015; Flowerdew y Richardson, 2017).

El centro del análisis de contenido engloba el estudio de las publicaciones de Twitter, investigadas durante dos periodos muestrales, que abarcan la semana anterior y posterior correspondientes al inicio de la pandemia en cada uno de los países seleccionados (P1), y desde la semana anterior hasta la semana posterior del fin de las medidas más restrictivas de cada estado (P2).

Concretamente, en Estados Unidos el periodo de alarma comienza el 13 de marzo tras la aparición pública del presidente, superando sus pre-teorías sobre la detención de la propagación del virus. El estudio del Twitter personal del presidente en el primer periodo (P1), se realiza desde el 6 hasta el 20 de marzo de 2020. Este episodio de primer periodo de alarma finaliza el 30 de abril de 2020, fecha en la que el presidente Donald Trump, anuncia el comienzo de la reapertura económica, aunque algunos estados ampliasen la orden de "stay at home", como New York, hasta el 15 de mayo. En consecuencia, se analizan las publicaciones difundidas durante el segundo periodo (P2) que transcurre desde el 23 de abril hasta el 7 de mayo de 2020.

En Reino Unido, con Boris Johnson a la cabeza, no se toman las medidas determinantes hasta el 23 de marzo. Antes de esta fecha, el primer ministro aconseja medidas cautelares sin establecer un periodo de alarma o de emergencias como la mayoría de países. Los esfuerzos se centran en la obligación de cumplir las normas establecidas. En esta fecha se anuncia un confinamiento domiciliario obligatorio, por lo que la muestra en Twitter se fija desde el 16 al 30 de marzo de 2020 (P1). Igualmente, para evaluar las fechas del fin del confinamiento, tomamos como referencia el 11 de mayo, cuando el líder da por finalizado el estado particular de 
limitación de la movilidad domiciliaria y comienza la desescalada (P2). Se evalúa las publicaciones emitidas entre el 4 y 18 de mayo de 2020.

La herramienta utilizada para el análisis es el programa de estadística informática SPSS de IBM Company? que recoge las diferentes variables dispuestas para gestar conceptos resultantes del compendio total de indicadores. Las cuentas de Twitter de los políticos seleccionados, nombradas cuentas oficiales por la red social, son el espacio digital más explotado por los referentes de este estudio. Trump es identificado como @realDonaldTrump, con más de 88.900 .000 usuarios, creada en marzo de 2009 y con el lema "45th President of the United States of America" en la cabecera de su perfil. Johnson determina su link de usuario, con la grafía de su nombre completo @BorisJohnson, con más de 3.100.000 millones de usuarios. Su unión a esta red data de 2015 y la leyenda que aparece en su perfil es "Prime Minister of the United Kingdom and @Conservatives leader. Member of Parliament for Uxbridge and South Ruislip."

El análisis a través de SPSS se realiza por cuantificación numérica, incluyendo variables cuantitativas donde se especifica el número de tuits vinculados con la COVID19, la cantidad de comentarios recibidos, el número de compartidos de cada tuit relacionado, la suma de favoritos, el recuento de falacias estipulada en los posts publicados y la recopilación de menciones particulares o genéricas que aparecen en las publicaciones. Igualmente, se contabilizan las etiquetas (nombramientos dirigidos) referidas a la oposición política o medios de comunicación y las auto-atribuciones meritorias de los mensajes.

Las variables cualitativas evidencian la localización de la fake news, el tema de la falacia, si el tono del comentario es positivo o negativo y si el contenido de los tuits aparece publicado en alguno de los medios seleccionados.

Por último, el análisis discursivo concentra la atención en el análisis de la apelación como recurso retórico del lenguaje. Se distinguen tres tipos de apelaciones: a la autoridad, a la emoción y a la ignorancia.

${ }^{7}$ SPSS deIBM Company: Plataforma de estadística para el análisis de variables. 
Toro González, S. y Pérez-Curiel, C. Populismo político en tiempos de COVID. Análisis de la estrategia de comunicación de Donald Trump y Boris Johnson en Twitter

Tabla 1. Metodología de investigación empleada en el análisis de Twitter

\begin{tabular}{|c|c|c|c|c|}
\hline $\begin{array}{c}\text { CUENTAS } \\
\text { DE } \\
\text { TWITTER }\end{array}$ & $\begin{array}{l}\text { TIPOLOGÍA DE } \\
\text { FUENTES }\end{array}$ & $\begin{array}{c}\text { VARIABLES } \\
\text { CUANTITATIVAS }\end{array}$ & $\begin{array}{c}\text { VARIABLES } \\
\text { CUALITATIVAS }\end{array}$ & $\begin{array}{c}\text { VARIABLES } \\
\text { DISCURSIVAS }\end{array}$ \\
\hline $\begin{array}{l}\text { - Donald } \\
\text { Trump } \\
\text { - Boris } \\
\text { Johnson }\end{array}$ & $\begin{array}{l}\text { @realDonaldTrump } \\
\text { @BorisJohnson }\end{array}$ & $\begin{array}{l}\text { - Tuits } \\
\text { - Comentarios } \\
\text { - Retuits } \\
\text { - Favoritos } \\
\text { - Fakes } \\
\text { - Etiquetas } \\
\text { - Atribuciones }\end{array}$ & $\begin{array}{ll}\text { - } & \text { Localización de la } \\
& \text { fake news } \\
\text { - } & \text { Temática } \\
\text { - } & \text { Tono del } \\
\text { comentario } \\
\text { - } \\
\begin{array}{l}\text { Presencia en } \\
\text { medios }\end{array}\end{array}$ & $\begin{array}{l}\text { - Apela a la } \\
\text { autoridad } \\
\text { - Apela a la } \\
\text { emoción } \\
\text { - Apela a la } \\
\text { ignorancia }\end{array}$ \\
\hline
\end{tabular}

Fuente: Elaboración propia

\section{DISCUSIÓN}

Las estrategias de la comunicación política y la influencia del discurso de los líderes sobre el electorado y la ciudadanía a través de las redes sociales se multiplican en situaciones de crisis de cualquier índole y origen (Gelpi, 2018). La COVID-19 es un ejemplo evidente del comportamiento de los representantes políticos en las continuadas exposiciones públicas frente a una situación de inestabilidad política y económica, rodeada de inseguridad y desorden social.

El primer espacio temporal analizado, nos proporciona un muestreo del total de sus publicaciones en las que el $60.65 \%$ son de contenido relacionados con la pandemia de Coronavirus, la afección en la sociedad, las medidas aplicadas y las causas y las consecuencias de la enfermedad. El resultado alcanza un total de 135 tuits sobre la COVID-19, publicados por los representantes políticos (Trump 82; Johnson, 53).

En la segunda fase investigada, se muestra un conteo de un total de 261 tuits publicados durante los 14 días analizados (Trump 196; Johnson 65), de los que 107 fueron dedicados a la COVID-19 (Trump 50 y Johnson 57), un porcentaje que expone la elevada dedicación de Johnson a la información sobre el virus. Comparándolo con el periodo anterior, el líder republicano y el líder conservador aumentan la cantidad de emisiones digitales, debido a la información institucional que genera el cambio de fase.

\subsection{Bloque de Cuantificación}

Tras el prólogo de datos generales sobre las cuentas de los políticos, vamos a establecer el enfoque cuantitativo inicial entre la relación de tuits, las interacciones de los usuarios en los perfiles de los personajes analizados, a través de likes, retuits y comentarios, y la comparación entre los periodos investigados.

En el primer periodo, destacan Donald Trump a la cabeza de publicaciones de Twitter con 82 posts, un $35.36 \%$ más de publicaciones que el dirigente inglés. En 
Toro González, S. y Pérez-Curiel, C. Populismo político en tiempos de COVID. Análisis de la estrategia de comunicación de Donald Trump y Boris Johnson en Twitter

cambio, en el segundo periodo, se observa que, es el líder inglés, Boris Johnson quien ha usado la red social en más ocasiones.

Tabla 2. Análisis Cuantitativo, interactividad de publicación sobre la COVID-19

\begin{tabular}{|c|c|c|c|c|c|c|}
\hline Métrica Twitter & \multicolumn{2}{|c|}{ Donald Trump } & \multicolumn{2}{c|}{ Boris Johnson } & \multicolumn{2}{c|}{ TOTAL } \\
\hline Periodo & P1 & P2 & P1 & P2 & P1 & P2 \\
\hline $\begin{array}{c}\text { No Tuits } \\
\text { relacionados }\end{array}$ & 82 & 50 & 53 & 57 & 135 & 107 \\
\hline No Likes & 10.078 .142 & 6.062 .825 & 1.249 .462 & 445.718 & 11.327 .604 & 6.508 .543 \\
\hline No Retuits $^{0} 2.713 .658$ & 1.410 .269 & 373.852 & 75.407 & 3.087 .510 & 1.485 .676 \\
\hline No Comentarios $^{0}$ & 1.723 .198 & 1.073 .124 & 153.620 & 92.757 & 1.876 .818 & 1.165 .881 \\
\hline
\end{tabular}

Fuente: Elaboración propia

Donal Trump muestra mayor número de likes en ambos periodos, con una ventaja cuatro veces mayor a sus propios retuits y seis veces superior a los likes conseguidos por Boris Johnson. Esta cuestión de métricas invita a reflexionar sobre la interacción que mantiene Trump con sus seguidores, ya que los retuits generan visibilidad y favorecen la difusión del mensaje. Trump se encuentra en retuits muy por debajo de su porcentaje de likes, con la particularidad que el retuit alcanza doble valor en la red, dada la capacidad de conseguir que el original se viralice y se posicione en el timeline (Carrasco-Polaino et al., 2018).

Respecto al número de falacias detectadas, el mayor porcentaje de noticias falsas se le atribuye al líder americano con el 26.8\%(P1) / 26\%(P2) frente a los porcentajes conseguidos por el primer ministro británico con tan solo el 9.4\% (P1) / 12.29\% (P2). 
Toro González, S. y Pérez-Curiel, C. Populismo político en tiempos de COVID. Análisis de la estrategia de comunicación de Donald Trump y Boris Johnson en Twitter

Tabla 3. Análisis cuantitativo de gráficas fakes

\begin{tabular}{|c|c|c|c|c|c|c|c|c|}
\hline & \multicolumn{2}{|c|}{ Frecuencia } & \multicolumn{2}{c|}{ Porcentaje } & Frecuencia & \multicolumn{2}{c|}{ Porcentaje } \\
\hline & P1 & P2 & P1 & P2 & P1 & P2 & P1 & P2 \\
\hline SÍ & 22 & 18 & $26.82 \%$ & $26 \%$ & 5 & 2 & $9.4 \%$ & $12.29 \%$ \\
\hline NO & 60 & 32 & $73.17 \%$ & $64 \%$ & 48 & 55 & $90.6 \%$ & $87.71 \%$ \\
\hline TOTAL & 82 & 50 & $100 \%$ & $100 \%$ & 53 & 57 & $100 \%$ & $100 \%$ \\
\hline
\end{tabular}

Fuente: Elaboración propia

Para finalizar el análisis cuantitativo, se plasma la comparativa entre las variables de 'etiqueta', denominación que recoge el ataque de ambos líderes a la oposición y/o los medios de comunicación, y 'atribución', méritos referidos a otras fuentes o a sí mismos.

Tabla 4. Análisis cuantitativo de etiquetas y atribuciones

\begin{tabular}{|c|c|c|c|c|c|c|c|c|}
\hline & \multicolumn{2}{|c|}{ Etiquetas } & \multicolumn{2}{c|}{$\%$} & \multicolumn{2}{c|}{ Atribuciones } & \multicolumn{2}{c|}{$\%$} \\
\hline Donald Trump & 23 & 17 & $38.33 \%$ & $53.12 \%$ & 44 & 36 & $52.38 \%$ & $58.06 \%$ \\
\hline Boris Johnson & 16 & 2 & $26.66 \%$ & $6.25 \%$ & 17 & 18 & $20.23 \%$ & $29.03 \%$ \\
\hline
\end{tabular}

Fuente: Elaboración propia

La comparativa en cuanto a las atribuciones muestra un número más elevado de atribuciones propias en ambos periodos, relativas fundamentalmente a su posición ideológica.

\subsection{Bloque de Cualificación}

La temática donde se localiza mayor número de falacias es la denominada "Acciones ejecutadas por el gobierno" con un total de 17 noticias fakes en el primer periodo (14 Trump; 3 Johnson), al igual que en el P2 con un total de 13 fakes (12 Trump; 1 Johnson). La diferencia entre Trump y Boris Johnson en este ítem estriba en el alto porcentaje de ataques que el presidente de Estados Unidos dedica a la oposición y a los medios de comunicación para justificar sus decisiones sobre la pandemia.

Otros temas en los que aparecen también noticias falsas, aunque en menor medida, son 'afección del virus', 'declaraciones del gobierno', 'sucesos con la ciudadanía' y 'propuestas de medidas'. 


\section{Fakes de Donald Trump}
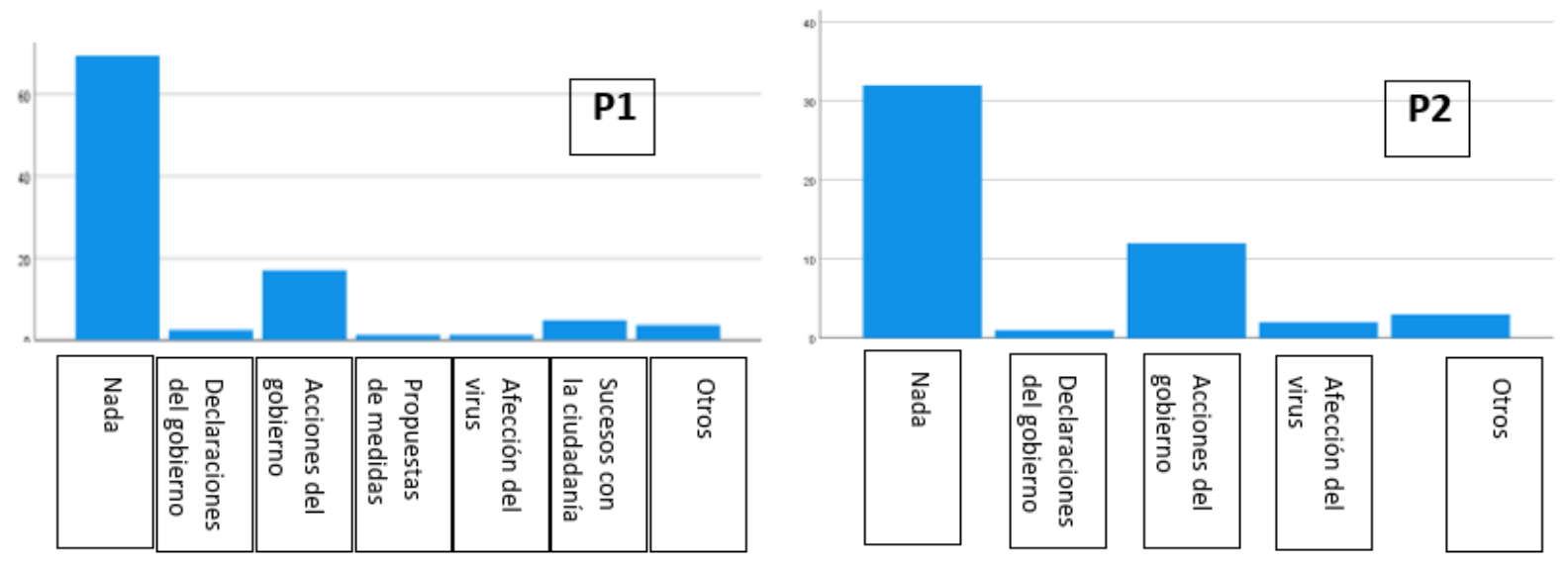

Fakes de Boris Johnson
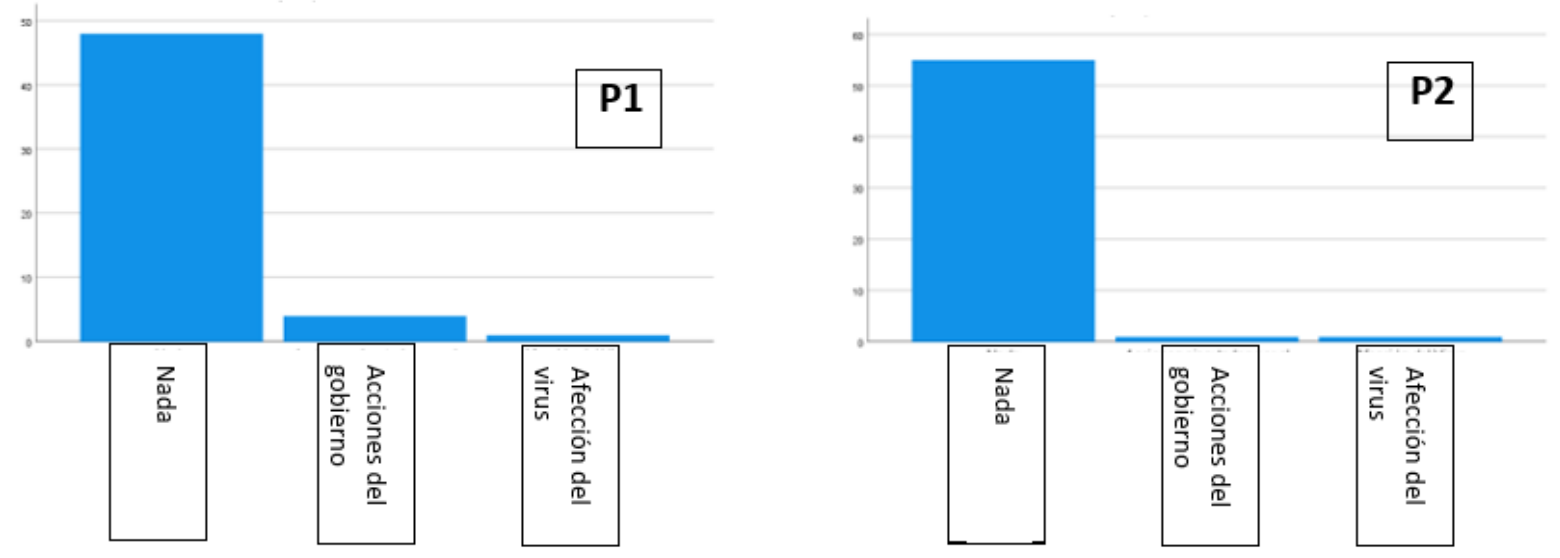

Gráfica 1. Análisis cualitativo temas de fakes

Fuente: Elaboración propia

Otro de los aspectos cualitativos tratados tiene que ver con el tono del mensaje. El tono de comunicación en Twitter es informal. Es importante anotar que en algunas ocasiones la limitación de los 280 caracteres puede dificultar e implementar el tono de comunicación adecuado (Mejías-Llanos, 2019).

La influencia de la posición que el candidato conservador y el republicano ocupan como dirigentes de cada país, evidencia el porcentaje de mensajes positivos que acumulan en los dos periodos. En ambos análisis, los comentarios positivos, superan a los negativos duplicando la cantidad. Trump alcanza 61 mensajes en (P1) / 31 (P2) mensajes con tono positivo, frente a 21(P1) / 19 (P2) negativos. Por su parte, Johnson registra 37 (P1) / 36 (P2) positivos frente a 16 (P1) / 21 (P2) negativos. La necesidad de alentar a la ciudadanía en tiempos de pandemia queda acreditada. 
Toro González, S. y Pérez-Curiel, C. Populismo político en tiempos de COVID. Análisis de la estrategia de comunicación de Donald Trump y Boris Johnson en Twitter

Tabla 5. Análisis cualitativo tono del mensaje

\begin{tabular}{|c|c|c|c|c|c|c|c|c|}
\hline & \multicolumn{2}{|c|}{ Frecuencia } & \multicolumn{2}{|c|}{ Porcentaje } & \multicolumn{2}{|c|}{ Frecuencia } & \multicolumn{2}{|c|}{ Porcentaje } \\
\hline Periodo & P1 & P2 & P1 & $\mathrm{P} 2$ & $\mathrm{P} 1$ & $\mathrm{P} 2$ & P1 & P2 \\
\hline Positivo & 61 & 31 & $74.4 \%$ & $62 \%$ & 37 & 36 & $69.8 \%$ & $63.2 \%$ \\
\hline Negativo & 21 & 19 & $25.6 \%$ & $38 \%$ & 16 & 21 & $30.2 \%$ & $36.8 \%$ \\
\hline Total & 82 & 50 & $100 \%$ & $100 \%$ & 53 & 57 & $100 \%$ & $100 \%$ \\
\hline
\end{tabular}

Fuente: Elaboración propia

Por último, en el análisis de este enfoque, se contempla el impacto que los tuits de estos dirigentes tienen sobre los medios de comunicación. Se enumera la cantidad de tuits analizados que han sido noticia en los medios y que han aparecido en cualquier formato, modificando o marcando la agendad setting.

Los resultados revelan que la mayoría de los tuits de Trump han sido secundados con el 67.9 (P1) / 68 (P2) por los medios, con un total de 55 (P1) / 34 (P2) tuits publicados en diferentes empresas de comunicación, ya sea en su versión tradicional o digital.
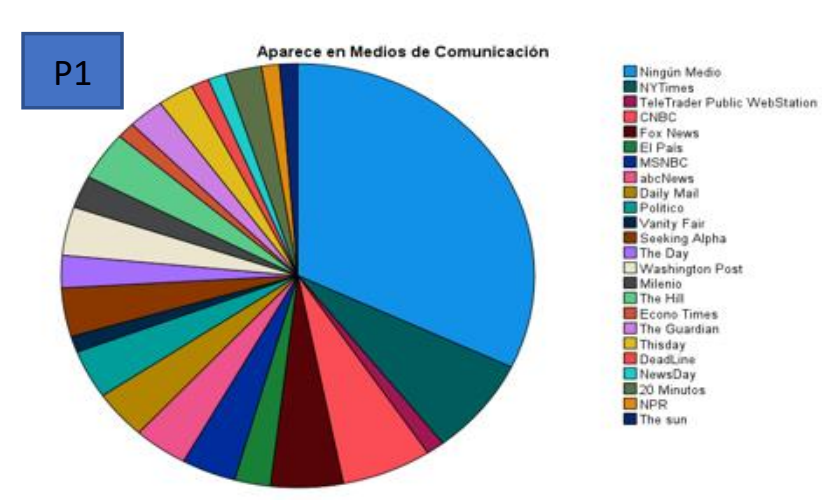

\begin{tabular}{|c|c|c|c|}
\hline NYTimes & 6 & Washington Post & 3 \\
\hline TeleTrader Public W & 1 & Milenio & 2 \\
\hline CNBC & 5 & The Hill & 3 \\
\hline Fox News & 4 & Econo Times & 1 \\
\hline El País & 2 & The Guardian & 2 \\
\hline MSNBC & 3 & Thisday & 2 \\
\hline ABC News & 3 & Deadiez & 1 \\
\hline Daily Mail & 3 & NewsDay & 1 \\
\hline Politico & 3 & 20 Minutos & 2 \\
\hline Vanity Fair & 1 & NPR & 1 \\
\hline Seeking Alpha & 3 & The Sun & 1 \\
\hline
\end{tabular}

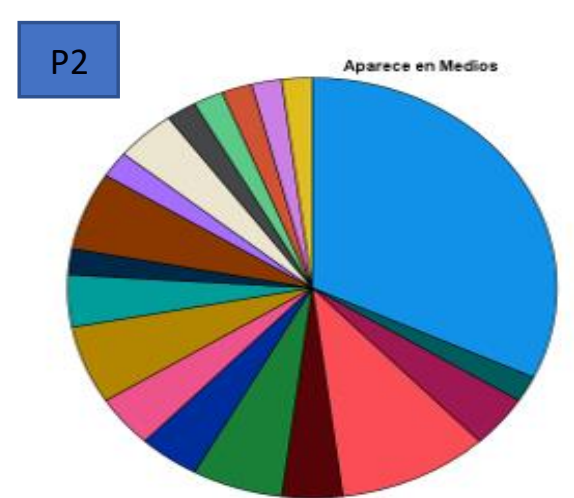

\begin{tabular}{|c|c|c|c|}
\hline Worid Socialist & 1 & 20 Minutos & 1 \\
\hline ABC News & 2 & Vox & 3 \\
\hline NYTimes & 5 & BBC & 1 \\
\hline CNN & 2 & Fox NewS & 2 \\
\hline Politico & 3 & NewsWeek & 1 \\
\hline As USA & 2 & Deadline & 1 \\
\hline Los Angeles Times & 2 & TASS & 1 \\
\hline Washington Post & 3 & NCB & 1 \\
\hline The Hill & 2 & MSNBC & 1 \\
\hline
\end{tabular}

Gráfica 2. Análisis cualitativo aparición en Medios de Comunicación, Trump

Fuente: Elaboración propia

Igualmente, evaluamos la influencia de Johnson en los medios, en los dos periodos estudiados. En este caso se alcanzan 41 publicaciones (P1) / 35 (P2) proyectadas en los medios y superando, en el primer periodo, la cobertura que los medios han dedicado al magnate estadounidense. 


\begin{tabular}{|c|c|c|c|}
\hline Financial Times & 6 & Clarín & 1 \\
\hline Expressamdstar & 2 & Telam & 1 \\
\hline Jerseyeveningpost & 1 & Harvard Business RH & 1 \\
\hline The Telegraph & 10 & Daily Mail & 1 \\
\hline LBC & 1 & The Straitstimes & 1 \\
\hline BBC News & 5 & AS English & 2 \\
\hline The Guardian & 2 & CheshireLive & 1 \\
\hline Telegraphandargus & 1 & The Sun & 1 \\
\hline France 24 & 2 & RPP Noticias & 1 \\
\hline Metro & 1 & The Day & 2 \\
\hline
\end{tabular}
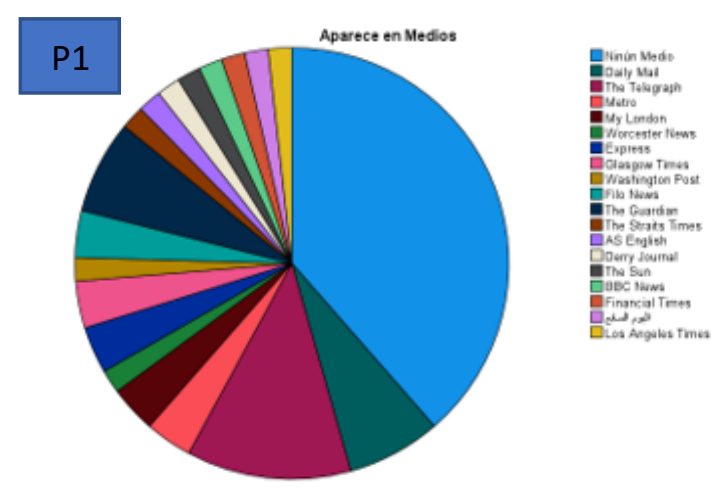

\begin{tabular}{|c|c|c|c|}
\hline Daily Mail & 4 & The Guardian & 4 \\
\hline The Telegraph & 7 & The Straits Times & 1 \\
\hline Metro & 2 & AS English & 1 \\
\hline My London & 2 & Derry Journal & 1 \\
\hline Worcester News & 1 & The Sun & 1 \\
\hline Express & 2 & BBC News & 1 \\
\hline Glasgow Times & 2 & Financial Times & 1 \\
\hline Washington Post & 1 & Aljazeera Magazine & 1 \\
\hline Filo News & 2 & Los Angeles Times & 1 \\
\hline
\end{tabular}
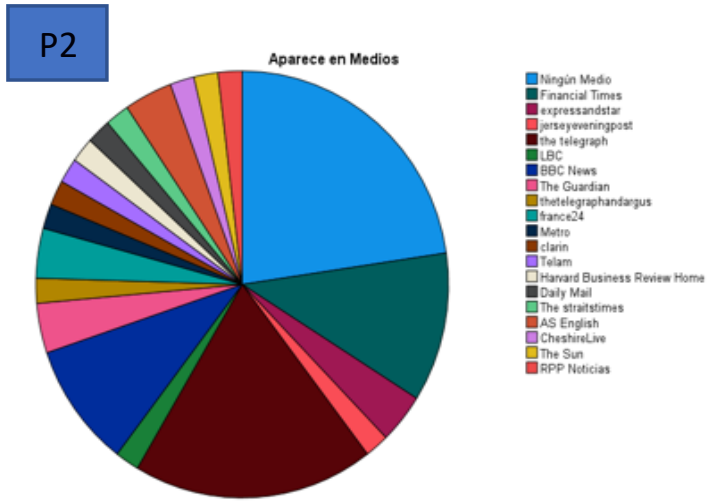

Gráfica 3. Análisis cualitativo aparición en Medios de Comunicación, Johnson

Fuente: Elaboración propia

\subsection{Bloque de Discursividad}

El enfoque discursivo atiende a considerar el acto de lenguaje, por una parte, como un acto de enunciación, de titulación, atendiendo al rol activo de los sujetos que intervienen en el discurso, y, por otra parte, como un acto de textualización que resulta en la construcción de un texto. Un enfoque discursivo consiste en formar una actividad de construcción de representaciones entre los interlocutores y el mundo referencial (Álvarez, 2006).

El paradigma discursivo se resuelve en el estudio atendiendo a las apelaciones relativas a la emoción, la ignorancia y la autoridad, que contienen los mensajes publicados por ambos líderes. 


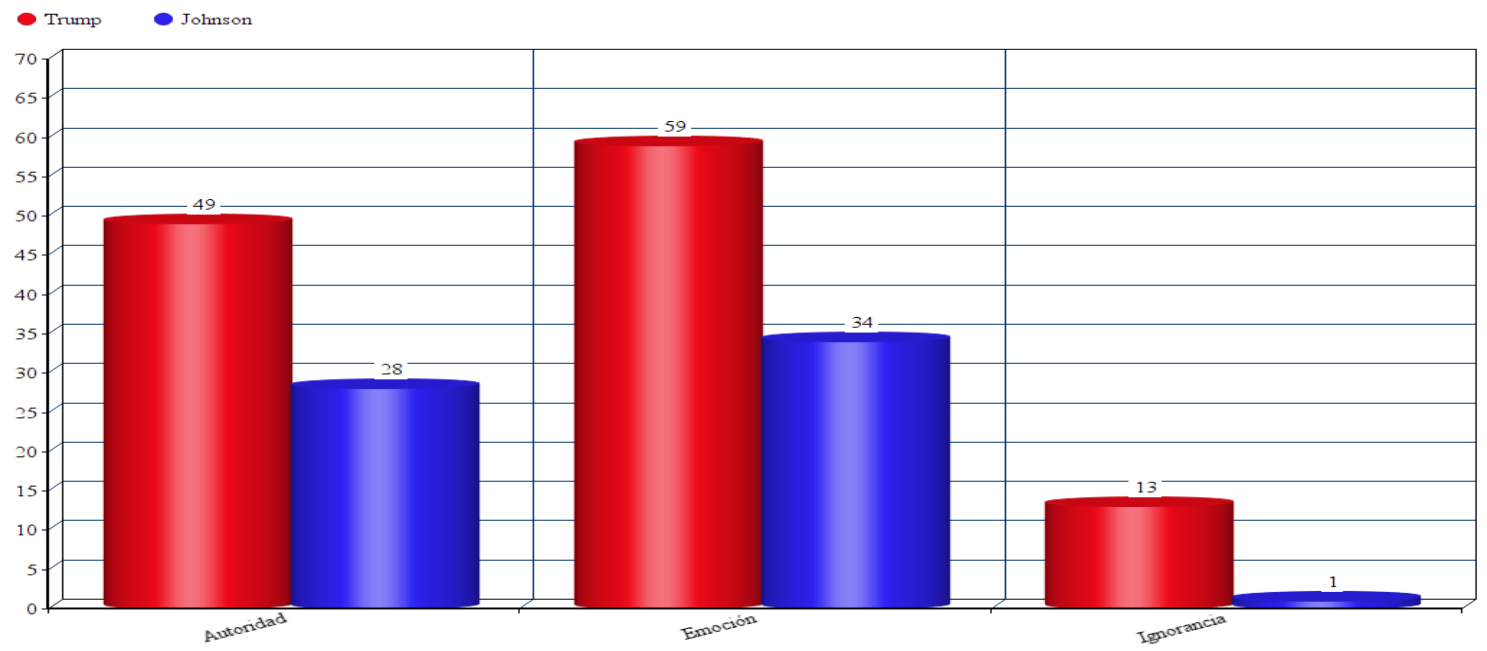

Gráfica 4. Tipología de apelaciones y niveles de uso en Twitter en el primer periodo Fuente: Elaboración propia

Comprobamos en la gráfica P1 que la demanda de emoción es, por excelencia, el apelativo más recurrente de los líderes en las redes sociales. En este primer periodo analizado, Trump apela a estos sentimientos en el $71.95 \%$ de sus publicaciones. Estos datos se diferencian con la injerencia de Johnson que respecto a la emoción es más liviano con el $64.15 \%$, aunque continúa superando la mitad de los posts emitidos.

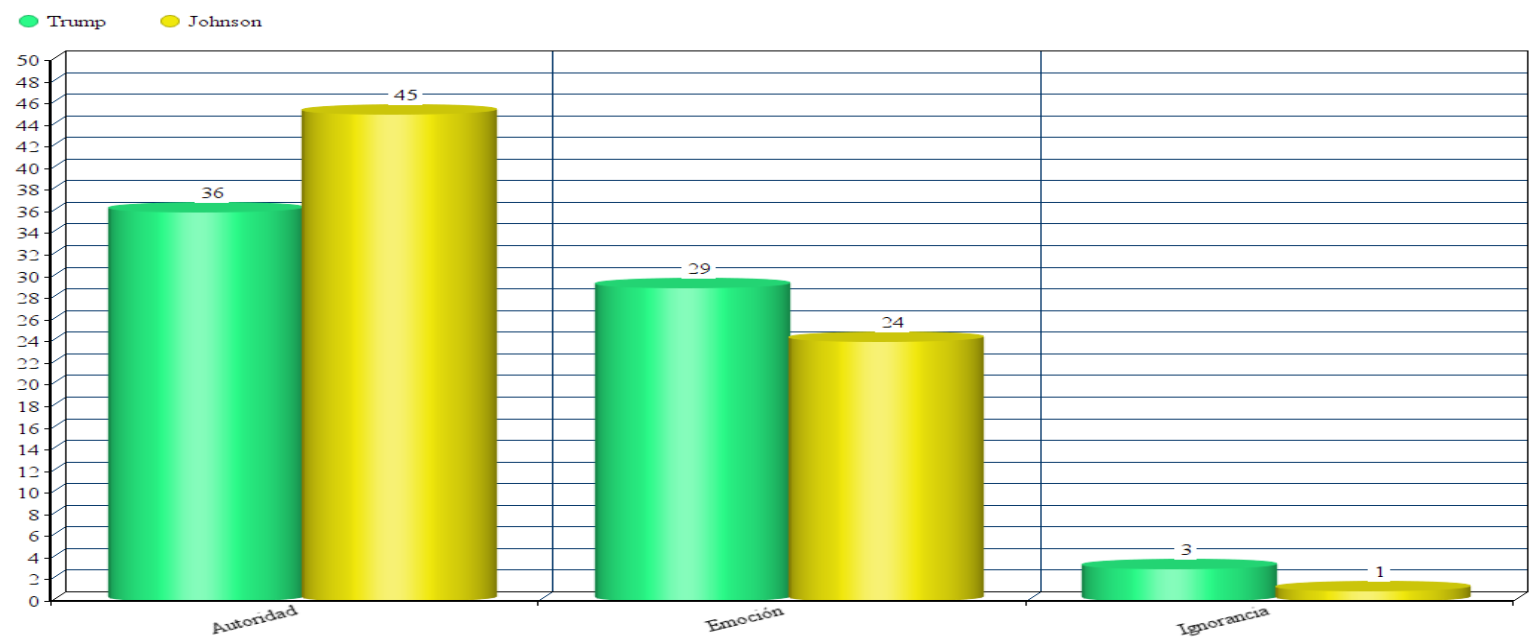

Gráfica 5. Tipología de apelaciones y niveles de uso en Twitter en el segundo periodo

Fuente: Elaboración propia

En P2, la emoción sigue siendo una de las apelaciones más utilizada en las publicaciones, aunque se posiciona por detrás de 'autoridad'. La variable 'autoridad' ocupa el primer lugar del ranking. Junto a esta evolución, es Boris Johnson quien adelanta al líder americano para colocarse en el puesto principal. Acumula un total de 
Toro González, S. y Pérez-Curiel, C. Populismo político en tiempos de COVID. Análisis de la estrategia de comunicación de Donald Trump y Boris Johnson en Twitter

45 referencias atribuidas a su posicionamiento de gobernante $(78.94 \%)$ frente a las alcanzadas por Trump (72\%).

Finalmente, la apelación a la ignorancia es un recurso menos utilizado por los líderes en ambos periodos. En este sentido, Trump utiliza un 15.85\% (P1) / 18.75\% (P2) de sus intervenciones digitales para apelar a la ignorancia de algunos usuarios sobre temas concretos. Frente a estos datos, el líder británico otorga menos protagonismo a este apelativo con el 1.89\% (P1) / 1.75\% (P2) de los tuits publicados.

\section{CONCLUSIONES}

El populismo y la propaganda han invadido las redes sociales favoreciendo el uso de la falacia, la distorsión comunicativa y la infoxicación de la ciudadanía. Inmersos en un periodo de alarma sin precedentes para la sociedad actual, se recurre a investigaciones previas (Pérez-Curiel y Velasco-Molpeceres, 2020; Pérez-da-Silva, et. al. 2020; Salaverría et al., 2020) que profundizan en el uso de las redes sociales y en los mecanismos de control de falacias, con la aportación de un sistema de auditoría y verificación para combatir la desinformación.

Igualmente, afirmar que todo mensaje falaz, con visibilidad pública, es un bulo premeditado o/e intencionado, supone hacer un juicio subjetivo. La realidad es más compleja, ya que la producción de contenido falso se debe a diferentes motivaciones como la información exagerada y la vinculación de diferentes elementos inconexos, una afirmación descontextualizada o una mala interpretación (Redondo, 2018).

Respecto a los objetivos específicos marcados, la muestra permite conocer la actividad de los líderes en Twitter durante la pandemia, su influencia y la veracidad de las publicaciones en los dos periodos analizados.

La falacia se identifica como marca del discurso de la apelación a la emoción, a la ignorancia y a la autoridad del líder (PI1). Estos valores representan la idiosincrasia del populismo conservador. La mayoría de los mensajes concentrados en la temática de la COVID-19 refuerzan la premisa de la sobrexposición y la publicación de fakes, durante el periodo de pandemia (Pérez-Curiel y Limón-Naharro, 2019).

La segunda premisa (PI2) confirma la influencia de los líderes en los medios. Los datos constatan que más de un $60 \%$ de los mensajes han sido difundidos en medios convencionales, en cualquiera de sus formatos. En este sentido, se evidencia el interés de los candidatos por conseguir rédito electoral, tal y como avanzan otros estudios previos (Redondo, 2018).

Los mecanismos de apelación a la ignorancia, a la autoridad y a la emoción confirman la presencia de marcas del populismo de extrema derecha en los mensajes publicados en Twitter (PI3). La interacción con las comunidades de fans, los likes, retuits y comentarios sobre los temas publicados y su influencia como presidentes del gobierno son rasgos de la personalidad de ambos candidatos. 
La conclusión acontecida no solo plantea los resultados expuestos. Indistintamente, podemos destacar las dificultades halladas en la investigación, como: encontrar posts modificados o eliminados, al estudiar un elemento tan vivo como Twitter. La modificación de mensajes por parte de los responsables de las divulgaciones o la clausura de publicaciones por parte de Twitter al descubrir que faltaban a algunas de las normas que debes cumplir para usar sus espacios digitales, son las evidencias más notorias. Igualmente, estas acciones son útiles para afianzar la segunda hipótesis donde se especifica la existencia de marcas del discurso populista en los mensajes, con un exponente superior que obliga a actuar sobre ellos. Otra dificultad destacada se ha hallado al intentar contextualizar al líder de Vox, Santiago Abascal, dentro del análisis, para comparar ideologías afines de distintos países donde se incluyera España, pero la connotación de no gobernar en el estado, desvirtuaba la realidad de la investigación.

Por último, en un estado de alarma y crisis mundial sin precedentes, en el que el populismo, la propaganda y la desinformación han invadido las redes sociales produciendo efectos de infoxicación en la ciudadanía, se plantean futuras líneas de investigación relacionadas con el estudio del papel de los medios como verificadores de la información en un sistema en el que prima la falacia y la propaganda de los líderes políticos y de los nuevos actores digitales. Indistintamente, se podría ampliar el estudio de las comunicaciones de los líderes mundiales por ideología, como representante de sus partidos, no con el carácter institucional que ha sido tratado en el actual análisis. Ampliar el estudio comparando las distintas Redes Sociales y qué discurso se utiliza en cada una de ellas, para qué tipo de colectivo está determinada la publicación en cada canal, es otra línea a considerar. Y como última posible línea de futura investigación, se plantea estudiar la influencia ideológica en la sociedad que consume este tipo de comunicación directa de los líderes.

Es esencial potenciar la hibridación de los medios tradicionales y digitales y marcar sus diferencias, para que cada plataforma ocupe el espacio que le pertenece, sin olvidar la responsabilidad social que garantice la veracidad de la información política y de cualquier ámbito.

\section{REFERENCIAS}

Acha Ugarte, B. (2017). Nuevos partidos de ultraderecha en Europa occidental: el caso de los republikaner alemanes en Baden-Württemberg. Universidad Autónoma de Madrid: Facultad de Derecho.

Alonso-Muñoz, L., \& Casero-Ripollés, A. (2017). Transparencia y monitorización en el entorno digital. Hacia una tipología de las plataformas impulsadas por la ciudadanía. Revista Latina de Comunicación Social, 72, 1.351-1.366. https://10.4185/RLCS$\underline{2017-1223}$

Álvarez, G. (2006). Un enfoque discursivo/textual para la enseñanza de idiomas. Chile: Universidad de la Concepción. 
Toro González, S. y Pérez-Curiel, C. Populismo político en tiempos de COVID. Análisis de la estrategia de comunicación de Donald Trump y Boris Johnson en Twitter

Bessi, A. y Ferrara, E. (2016). Los bots sociales distorsionan la discusión en línea de las elecciones presidenciales de EE. UU. de 2016. 2020, de Information Sciences Institute.

https://www.isi.edu/people/ferrarae/publications/social bots distort 2016 us pre sidential election online discussion

Boczkowski, P. (2016). Las noticias falsas y el futuro del periodismo. La posverdad. Anfibia. http://www.revistaanfibia.com/ensayo/la-postverdad/

Bosch, J.-R., Brunet, F. y Rosiñol, J. (2017). Realidad virtual, posverdad y populismo. El confidencial. https://blogs.elconfidencial.com/mundo/tribunainternacional/2017-01-20/populismo-politica-realidad-virtual-brexittrump 1318989/

Bravo Martos, A. I. (2020). Influencia y liderazgo político en tiempos de Brexit. Análisis de las estrategias de Boris Johnson en Twitter y efectos en los medios. Facultad de Comunicación de la Universidad de Sevilla.

Brennen, J. S., Simón, F. M., Howard, P. N., \& Nielsen, R. K. (2020). Types, sources, and claims of COVID-19 misinformation. Reuters Institute.

Carrasco Polaino, R., Cirujano, E., \& Fuentes, L. (2018). Twitter como herramienta de comunicación política en el contexto del referéndum independentista catalán: asociaciones ciudadanas frente a instituciones públicas. Revista ICONO14 Revista científica de Comunicación y Tecnologías emergentes. 16(64). https://doi.org/10.7195/ri14.v16i1.1134

Castillo-Esparcia, A., Fernández-Souto, A. B. y Puentes-Rivera, I. (2020). Comunicación política y Covid-19. Estrategias del Gobierno de España. Profesional de la información. 29(4), e290419. https://doi.org/10.3145/epi.2020.jul.19

Chadwick, L., \& Cereceda, R. (2020). La cloroquina e hidroxicloroquina contra el Covid19 ¿Una esperanza?. Euronews. https://es.euronews.com/2020/03/24/empiezanlos-ensayos-clinicos-con-cloroquina-contra-el-covid-19-una-esperanza

Charaudeau, P. (2009). Discurso y Sociedad. Paris: Universidad de París 13 Centro de Análisis del Discurso.

Costa-Sánchez, C. y López-García, X. (2020). Comunicación y crisis del coronavirus en España. Primeras lecciones. El profesional de la información, 29(3), e290304. https://doi.org/10.3145/epi.2020.may.04

Coughlan, S. (2017). Qué es la "posverdad", el concepto que puso de moda el "estilo Trump" en Estados Unidos. BBC. http://www.bbc.com/mundo/noticiasinternacional-38594515 
Toro González, S. y Pérez-Curiel, C. Populismo político en tiempos de COVID. Análisis de la estrategia de comunicación de Donald Trump y Boris Johnson en Twitter

Cuervo, B. (2015) El ascenso de Hitler y del partido nazi al poder en Alemania. Historia Digital, XV (26) ISSN 1695-6214

Dader, J. L. y Eva Campos-Domínguez (coords.). (2017). La búsqueda digital del voto. Cibercampañas electorales en España 2015-16. Valencia: Tirant Lo Blanch.

Ebata, M. (1997). Right-Wing Extremism: In Search of a Definition. En The Extreme Right: Freedom and Security at Risk. Ariel Braun y Stephen Scheinberg (Eds). Boulder: Westview Press.

Elias, C. (2018). Fakenews, poder y periodismo en la era de la posverdad y 'hechos alternativos'. Ámbitos. Revista Internacional de Comunicación. 19-24. https://doi.org/10.12795/Ambitos. 2018.i40.04

Fernández-Torres, M., Almansa Martínez, A., \& Chamizo-Sánchez, R. (2021). Infodemic and Fake News in Spain during the COVID-19 Pandemic. International Journal of Environmental Research and Public Health. 18, 1781. https://doi.org/10.3390/ijerph18041781

Flowerdew, J. y Richardson, J. E. (2017). The Routledge Handbook of Critical Discourse Studies. London: Routledge.

Gelpi Texeira, R. (2018). Política 2.0: las redes sociales (Facebook y Twitter) como instrumento de comunicación política. Madrid: Universidad Complutense de Madrid. Facultad de Ciencias Políticas y Sociología. Departamento de Sociología.

Gerbaudo, P. (2014). Populism 2.0. In D. Trottier \& C. Fuchs (Eds.) Social media, politics and the state: Protests, revolutions, riots, crime and policing in the age of Facebook, Twitter and YouTube (pp. 16-67). New York: Routledge.

Gil Ramírez, M., Gómez de Travesedo Rojas, R., \& Almansa Martínez, A. (2020). YouTube y coronavirus: análisis del consumo de vídeos sobre la pandemia COVID19. Revista Latina De Comunicación Social, 78, 121-153. https://doi.org/10.4185/RLCS-2020-1471

Groshek, J. y Engelbert, J. (2013). Double differen- tiation in a cross-national comparison of populist political movements and online media uses in the United States and the Netherlands. New media \& society, 15(2), pp. 183- 202. https://core.ac.uk/download/pdf/18509281.pdf

Hansen, M., Roca-Sales, M., Keegan, J. y King, G. (2017). Artificial intelligence: Practice and implications for journalism. Columbia University Libraries. Tow Center for Digital Journalism. https://doi.org/10.7916/D8X92PRD

Hawkins, K. A. (2016) Populism and the 2016 U.S. Presidential Election in comparative perspective. Comparative Politics Newsletter, 26(2), 91-97. 
Toro González, S. y Pérez-Curiel, C. Populismo político en tiempos de COVID. Análisis de la estrategia de comunicación de Donald Trump y Boris Johnson en Twitter

Hermida, A. (2016). Trump and the triumph of affective news when everyone is the media. En D. Lilleker, D. Jackson, E. Thorsen \& A. Veneti (Eds.), US election analysis 2016: Media, voters and the campaign (p. 76). Poole: Centre for the Study of Journalism

Hernández-Santaolalla, V., \& Sola-Morales, S. (2019). Postverdad y discurso intimidatorio en Twitter durante el referéndum catalán del 1-O. Observatorio, 102121.

Krane, M. (2010): The socially filtered media agenda: a study of AgendaSetting among news outlets on Twitter. Columbia: University of Missouri.

Krippendorff, K. (2012). Content Analysis: An Introduction to Its Methodology. 3. a edición. Thousand Oaks, CA: Sage Publications.

Kupferschmidt, K. (2020). Preprints bring 'firehose' of outbreak data. Science, 367(6481), 963-964. http://doi.org/10.1126/science.367.6481.963

López-García, G. (2016). 'Nuevos' y 'viejos' liderazgos: la campaña de las elecciones generales españolas de 2015 en Twitter. Communication \& Society, 29(3), 149-167. https://www.doi.org/10.15581/003.29.3.sp

López-Noguero, F. (2002). El Análisis de contenido como método de investigación. Dialnet, 4, 167-180.

Mackintosh, J. (1791). Vindiciae Gallicae. Escocia: Mons de Calonne.

Mejía Llano, J. C. (2019). Tonos de comunicación en las redes sociales, el blog y el sitio web. guía comunicación digital con ejemplos + infografía: Consultor y Speaker de Marketing Digital y Transformación Digital.

Montoya, P., \& Vandehey, T. (2009). The brand called you. Create a personal branding that wins attention and grows your business. London: McGraw-Hill.

Mudde, C. (2016). Europe's populist surge: A long time in the making. Foreign affairs, 95, 25-30. https://www.foreignaffairs.com/articles/europe/2016-10-17/europespopulist-surge

Nocetti, Ó. (1990). Falacias y Medios de Comunicación. El discurso como arma. Editorial Humanitas.

Orozco Macias, A. F. (2021). Las redes sociales digitales como espacio para ser otro: una discusión teórica. Revista De Comunicación De La SEECI, 54, 1-17. https://doi.org/10.15198/seeci.2021.54.e639

Pano Alamán, A. (2020). La política del hashtag en Twitter. Italia: Università di Bologna. 
Toro González, S. y Pérez-Curiel, C. Populismo político en tiempos de COVID. Análisis de la estrategia de comunicación de Donald Trump y Boris Johnson en Twitter

Pérez-Curiel, C., Domínguez-García, R., \& Jiménez-Marín, G. (2021). Public Sphere and Misinformation in the U.S. Election: Trump's Audience and Populism Indicators in the COVID-19 Context. Journalism and Media. 2, 335-350. https://doi.org/10.3390/journalmedia2030020

Pérez-Curiel, C., \& Naharro, P. L. (2019). Influencers de la Política. Estudio de la marca personal de Donald Trump en Twitter y efectos en medios y usuarios. Communication \& Society, 57-76.

Pérez-Curiel, C., Rivas-de-Roca R., \& García-Gordillo, M., (2021). Impact of Trump's Digital Rhetoric on the US Elections: A View from Worldwide Far-Right Populism. Social Sciences, 10, 152. https://doi.org/10.3390/socsci10050152

Pérez-Curiel, C., \& Velasco-Molpeceres, A. M. (2020). Tendencia y narrativas de factchecking en Twitter. Códigos de verificación y fake news en los disturbios del Procés (14-0). AdComunica, 95-122. https://doi.org/10.6035/671

Pérez-Dasilva, J.-Á., Meso-Ayerdi, K., \& Mendiguren-Galdospín, T. (2020). Fake news y coronavirus: detección de los principales actores y tendencias a través del análisis de las conversaciones en Twitter. El profesional de la información, 29(3), e290308. https://doi.org/10.3145/epi.2020.may.08

Pérez-Ortega, A. (2014). Marca personal para dummies. Barcelona: PAPF. ISBN: 978 8432902055.

Powers, S., \& Kounalakis, M. (eds.). (2017). Can Public Democracy Survive the Internet? Bots, Echo Chambers, and Disinformation. U.S. Advisory Commission on Public Diplomacy (Department of State).

Rampersad, H. (2009). Authentic personal branding: A new blueprint for building and aligning a powerful leadership brand. San Bernardino, CA: IAP.

Redondo, M. (2018): La doctrina del post. Posverdad, noticias falsas...Nuevo lenguaje para desinformación clásica. En ACOP: https://compolitica.com/la-doctrina-delpost-posverdad-noticias-falsas-nuevo-lenguaje-para-desinformacion-clasica/

Román-San Miguel, A., Sánchez-Gey, N., \& Elías Zambrano, R. (2020). Las fake news durante el Estado de Alarma por COVID-19. Análisis desde el punto de vista político en la prensa española. Revista Latina de Comunicación Social, 78.

Salaverría, R., Buslón, N., López-Pan, F., León, B., López-Goñi, I., \& Erviti, M. C. (2020). Desinformación en tiempos de pandemia: tipología de los bulos sobre la Covid-19. El profesional de la información, 29(3), e290315. https://doi.org/10.3145/epi.2020.may.15 
Toro González, S. y Pérez-Curiel, C. Populismo político en tiempos de COVID. Análisis de la estrategia de comunicación de Donald Trump y Boris Johnson en Twitter

Shoemaker, P. J., Vos, T. (2009). Gatekeeping theory. Nueva York: Routledge. ISBN: 0415981387.

Silverman, D. (2016). Qualitative Research. London: SAGE.

Taggart, P. (2000). Populism. Buckingham: Open University Press

Tandoc, E. C. (2020). Commentary: how to stay sane in a time of Covid-19 information overload. Channel new Asia, 4 April. https://www.channelnewsasia.com/news/commentary/covid-19-coronavirusinformation-overload-fake-newshoaxes-12595334

Urmeneta, M. (2017, 20 de febrero). Lecciones verdaderas tras los "fake news". Aceprensa: http://www.aceprensa.com/articles/lecciones-verdaderas-tras-las-fakenews/

Valadier, P. (2017). La posverdad, peligro para la democracia. Revista de Fomento social, 72(2), 297-304.

Van Dijk, T. (2015). Critical discourse studies. A sociocognitive Approach. Methods of Critical Discourse Studies, 3(1), 63-74. https://www.researchgate.net/publication/265620660 Critical Discourse Studies A Sociocognitive Approach 1 Van-Kessel

Stijn Castelein, R. (2016). Shifting the blame: Populist politicians' use of Twitter as a tool of oppo- sition. Journal of contemporary European research, 12(2), 594-614. https://repository.lboro.ac.uk/articles/Shifting the blame Populist politicians use of Twitter as a tool of opposition/9469646

Xifra, J. (2020). Comunicación corporativa, relaciones públicas y gestión del riesgo reputacional en tiempos del Covid-19. El profesional de la información (EPI), 29(2).

\section{AUTORES:}

\section{Sergio Toro González}

Grado en Periodismo y Máster en Comunicación Institucional y Política por la Universidad de Sevilla. Compagina su actividad académica con las labores de Dircom de la Administración Pública. Cuenta con publicaciones en revistas y editoriales nacionales. En el plano profesional destaca por su experiencia en medios de comunicación y curso de especialización periodística. Sus principales intereses de investigación se orientan hacia la comunicación política institucional, el periodismo político y el impacto social de la desinformación sobre la esfera pública.

stg1985@hotmail.com

Orcid ID: https://orcid.org/0000-0003-2189-0797 
Toro González, S. y Pérez-Curiel, C. Populismo político en tiempos de COVID. Análisis de la estrategia de comunicación de Donald Trump y Boris Johnson en Twitter

\section{Concha Pérez Curiel}

Concha Pérez Curiel es doctora y profesora de Periodismo Político y Económico en la Facultad de Comunicación de la Universidad de Sevilla. Pertenece al grupo de investigación Communication \& Social Sciences (SEJ-619). Es miembro de Proyectos Estatales de I+D+I. Su línea de investigación se enmarca en la comunicación y el periodismo político, el marketing digital, el análisis de la desinformación y la calidad periodística. Cuenta con publicaciones en revistas científicas de impacto y editoriales de referencia internacional.

cperez1@us.es

Orcid ID: https://orcid.org/0000-0002-1888-0451

Google Scholar: https://scholar.google.es/citations?user=OSs6JZsAAAAJ\&hl=es

ResearchGate: https://www.researchgate.net/profile/Concha-Perez-Curiel

Scopus: https://www.scopus.com/authid/detail.uri?authorId $=57192428906$

Academia.edu: https://us.academia.edu/ConchaP\%C3\%A9rezCuriel 